\title{
CAPÍTULO 2 \\ O DESENVOLVIMENTO DAS FUNÇÕES PSÍQUICAS \\ SUPERIORES: ROMPENDO COM A DICOTOMIA ENTRE O NATURAL E O HISTÓRICO-CULTURAL*
}

\author{
Renata Linhares \\ Marilda Gonçalves Dias Facci
}

\section{Introdução}

A discussão das funções psíquicas superiores perpassa vários dos escritos de L. S. Vigotski, não de forma tangencial, mas como uma importante categoria nas formulações da Teoria Histórico-Cultural sobre o psiquismo humano. Inclusive, alguns pesquisadores buscaram nominar a teoria de Vigotski a partir desse conceito, como demonstrou Keiler (2012). Vigotski (2010) enfatiza a importância do conceito de desenvolvimento das funções psíquicas superiores como um dos mais importantes da Psicologia. Ele identificou que, até o momento de seus estudos, as análises realizadas por pesquisadores eram insuficientes e limitadas.

Para Martins (2013), o desenvolvimento do psiquismo consubstanciado na formação das funções psíquicas superiores é a categoria central na Psicologia HistóricoCultural. Segundo a autora, as contribuições de L. S. Vigotski, A. R. Luria e A. N. Leontiev são fundamentais para as investigações do desenvolvimento social do psiquismo humano, compreendido nesse sentido, como verdadeiro objeto da Psicologia científica.

Por considerar a relevância desse tema para a Psicologia e a Educação, esse texto busca explicitar o conceito do desenvolvimento das funções psíquicas superiores no entrelaçamento dos aspectos biológicos e culturais da natureza social do psiquismo humano. Daremos destaque para a apropriação cultural em seu desenvolvimento, apresentando a unidade contraditória das dimensões naturais e sociais, a importância da mediação para o desenvolvimento das funções psíquicas superiores e, por fim, as relações com a periodização do desenvolvimento.

\section{O desenvolvimento das funções psíquicas superiores: a relação entre o biológico e o social}

Para a Psicologia Histórico-Cultural as peculiaridades do psiquismo humano deveriam ser estudadas com base nos fundamentos do Materialismo Histórico-Dialético, contrapondo-se a uma Psicologia tradicional que desconsidera, dentre outros, os aspectos históricos das funções psíquicas humanas. Dessa forma, pondera-se imprescindível a relação entre o método materialista histórico-dialético com a Psicologia Histórico-Cultural. Esse posicionamento faz parte de um debate mais amplo, sobre a forma como a Psicologia Histórico-Cultural vem sendo apropriada no Brasil. Dentre alguns trabalhos que analisam os processos de tradução, distorções e censura do pensamento de Vigotski, retirando a vinculação com o materialismo histórico, destacamos Duarte (2006), Prestes (2012) e Tuleski (2008).

Para explicitar o desenvolvimento das funções psíquicas superiores, Vigotski (2010) retoma a discussão sobre a crise da Psicologia, momento em que se depara com múltiplas explicações quanto ao que seria o psiquismo. Para o autor, os conceitos apresentam-se

* DOI - 10.29388/978-65-86678-97-0-f.29-46 
polissêmicos e confusos, modificando segundo o ponto de vista básico do objeto investigado pelas diferentes concepções da Psicologia. A sistematização dos conhecimentos e a formação de princípios e leis fundamentais capazes de explicar o psiquismo humano, apresentam diferentes sistemas psicológicos, muitas vezes em tendências opostas, partindo de diversos princípios metodológicos. Ainda que a realidade seja a mesma, os aspectos teórico-cognitivos que as explicam são divergentes. Como identificava Luria (1979, p. 5), as pesquisas científicas não conseguiam explicar as "formas complexas de atividade psíquica do homem, que se manifesta na atividade consciente dos modos e procedimentos superiores de comportamento especificamente humanos, de atenção ativa, de memorização arbitrária e do pensamento lógico".

O conceito de desenvolvimento das funções psíquicas superiores aparece pela primeira vez nos manuscritos Psicologia Concreta do Homem ${ }^{1}$, de 1929, no entanto é aprofundado no volume III das Obras Escolbidas ${ }^{2}$, cujos cinco primeiros capítulos foram publicados em 1931. Para o autor, existe uma complexidade das funções psíquicas superiores enquanto fenômeno tipicamente humano e que se desenvolveria a partir da apropriação da cultura.

No primeiro capítulo do volume III das Obras Escolhidas, O problema do desenvolvimento das funções psíquicas superiores, Vigotski (2010) afirma que o estudo das funções psíquicas superiores não era muito explorado à época, por isso o conceito aparecia na literatura a partir de definições confusas. Isto posto, o autor começa seu trabalho a partir da crítica aos estudos que tentam decompor as funções psíquicas superiores em elementos constitutivos, pois desconsideram a qualidade fundamental quando as reduzem a processos elementares, perdendo também o caráter unitário e estrutural.

De acordo com Luria (1979) era preciso uma revisão radical do conceito de funções psíquicas, com mudanças fundamentais aos enfoques que partiam de princípios localizacionistas das funções cerebrais. Para o autor, um sistema funcional complexo não pode ser localizado em uma determinada área do sistema nervoso. No entanto, os primeiros estudos para a compreensão dos processos e fenômenos psíquicos humanos foram reproduzidos a partir de um percurso biológico, estabelecendo correlações diretas entre órgãos, suas formas de operação e as tarefas que possivelmente executavam. Para alguns pesquisadores, o funcionamento das atividades psíquicas deveria ter, portanto, correspondência no cérebro, sobretudo no córtex.

Tanto Vigotski (2010) quanto Luria (1979) reconhecem os avanços dessa concepção para a época, pois enfocam a relação entre os processos psíquicos e o cérebro, descolando as discussões do espiritual, de uma concepção metafísica, para a materialidade. No entanto, consideram que havia problemas e limites, já que buscavam uma localização da organização funcional do cérebro na compreensão dos processos psíquicos. Dessa forma, para entender as formas superiores, as investigações faziam análises, fracionando-as e reduzindo-as a uma série de processos elementares ou compreendendo as formas superiores e inferiores como estruturas petrificadas que não se relacionam.

A partir da crítica à Psicologia tradicional, que compreendia o processo de estruturação das formas complexas de comportamento como uma somatória mecânica de elementos isolados, a nova Psicologia centra seus estudos no todo e naquelas propriedades que não resultam da soma das partes. De acordo com Vigotski (2010), as formas superiores do psiquismo não se explicam pela existência de sínteses criativas que agrupam elementos isolados para formar novos processos, segundo a concepção atomística, que compreendia esses processos como naturais. Logo, era preciso substituir as investigações descritivas,

1 VIGOTSKI, L. S. Manuscritos de 1929. Educação \& Sociedade, n. 71, Campinas, jul. 2000

2 VYGOTSKI, L. S. Obras Escogidas - Tomo III. Disponível em: <http://www.taringa.net/perfil/ vygotsky >. Acesso em: 18 jul. 2010. Livro ainda não traduzido para o português, cujos capítulos, do sexto ao décimo quinto, foram publicados em 1960. 
quantitativas, mecânicas da Psicologia tradicional por uma postura investigativa dialética, capaz de analisar a realidade em sua totalidade.

O conceito de totalidade é central para o pensamento materialista dialético, pois é uma compreensão dinâmica, ao contrário das concepções metafísicas que tratavam totalidade como abstrato e atemporal, ou seja, as partes ocupando posição fixa em um todo inalterado. Para a concepção dialético-materialista, a totalidade é dinâmica, capaz de refletir as mediações e transformações da realidade objetiva, ou seja, envolve a unidade concreta de contradições e limita-se a um período histórico concreto determinado - "[...] toda a totalidade é feita de totalidades a ela subordinadas, e também que a totalidade em questão é, ao mesmo tempo, sobre determinada por totalidades de complexidade superior" (LUKÁCS apud BOTTOMORE, 2001, p. 381).

Luria (1979, p. 89) apresenta que o conceito de função para as ciências biológicas tem dois significados diversos. Um deles, mais restrito, é ligado a determinado tecido, com correlações diretas entre órgãos e formas de operação, que influenciou os estudos que procurassem no cérebro, principalmente no córtex cerebral, o funcionamento do psiquismo. O outro, mais amplo, designa a atividade de adaptação de todo o organismo, onde "a função se constitui numa complexa atividade, exercida pelo trabalho conjunto de todo um sistema de órgãos, cada um dos quais integra esse sistema funcional em seus papéis, assegurando esse ou aquele aspecto desse sistema funcional".

Luria (1979) apresenta que pesquisas fisiológicas, realizadas com certos neurônios, questionavam a homogeneidade da massa cerebral como um todo único, e as pesquisas psicofisiológicas e psicológicas mostravam que as funções psíquicas eram compostas por um número considerável de elos componentes. Portanto, o sistema funcional do psiquismo humano precisaria ser compreendido como um complexo dinâmico, considerando a diversificação e a especialização do córtex cerebral.

Vigotski (2010) reconhece que a natureza orgânica da estrutura está intimamente ligada à função, constituindo um todo, com uma reciprocidade no condicionamento entre a forma e a função. Os fenômenos morfológicos e fisiológicos se formam e a função fica condicionada a essa formação. As modificações na estrutura ocorrem diferenciando as partes e cada uma das partes isoladas cumpre diversas funções. Quando se unificam, as partes, em um processo global, produzem conexões funcionais que dobram as relações recíprocas das funções. O autor destaca que o processo de desenvolvimento cultural provoca mudanças fundamentais nessas estruturas iniciais, promovendo a aparição de novas estruturas que estabeleceram nova correlação com as partes. "O desenvolvimento segue não para a socialização, mas para a individuação de funções sociais (transformação das relações sociais em funções psicológicas)" (VIGOTSKI, 2000, p. 29). Assim, os estudos sobre o cérebro como um órgão material teve um papel decisivo na concepção de um psiquismo reflexo da realidade, com condições sociais objetivas interferindo no desenvolvimento. Isso porque a forma dialética reconhece a indissociabilidade entre o sistema nervoso e o mundo exterior.

Nesse sentido, o aprofundamento das investigações exigia métodos apropriados, rompendo com a dicotomia entre natural e histórico-cultural e entre biológico e social. As explicações da Psicologia eram insuficientes até então para explicar as relações entre os processos orgânicos e culturais do desenvolvimento do psiquismo humano. Eram necessários novos métodos de investigação, que inclú́ssem o desenvolvimento cultural, a vida social. Para Vigotski (2004), concomitantemente às mudanças metodológicas da investigação psicológica, modifica-se, inevitavelmente, o próprio caráter da análise psicológica e os conceitos.

A reivindicação não era apenas para implantar o historicismo na ciência psicológica, pois seria redundante e não apresentaria nada de novo. Era preciso compreender sobre qual Psicologia e sobre qual história estaria se referindo. O princípio da historicidade no 
método materialista histórico-dialético busca conferir as determinações gerais, aquelas que dizem respeito a um momento histórico. Em um estudo rigoroso, que vai além da aparência, busca descobrir leis gerais que orientam o movimento em uma perspectiva que revela seu caráter contraditório e transitório.

De acordo com Martins (2013), Vigotski introduziu, nas investigações psicológicas, a ideia de historicidade da natureza do psiquismo humano aliada à reorganização dos mecanismos naturais dos processos psíquicos, por decorrência da apropriação da cultura. A história real do desenvolvimento do psiquismo humano reflete a história da complexificação da vida em sociedade, sendo que o psiquismo humano só pode ser explicado na qualidade de construção social. A historicidade do ser humano relacionado às funções psíquicas superiores, expressa características que distinguem o homem como pertencente ao gênero humano.

Admitir a historicidade implica admitir que o gênero humano é resultado da atividade social e da experiência social acumulada nos produtos objetivos e subjetivos dessa atividade. Considerar a historicidade como o aspecto mais importante na definição do ser humano é admitir que gênero humano pode tornar-se sujeito de sua história, tornar-se sujeito do processo pelo qual a humanidade produz e reproduz a si mesma por meio de processos objetivos e subjetivos (DUARTE, 2006, p. 254).

Compreender o percurso histórico da humanidade, ou seja, o percurso do desenvolvimento filogenético, contribui para esclarecer o percurso do desenvolvimento ontogenético das funções psíquicas superiores. Assim, Vigotski (2010) faz várias críticas às teorias existentes, dentre elas a suposição de que as funções psíquicas superiores no processo de desenvolvimento da humanidade permaneceriam imutáveis, modificando somente o conteúdo da psique e o conjunto das experiências. Para essas teorias, a estrutura e as funções dos processos psíquicos seriam idênticas entre o homem primitivo e o homem atual. Essa explicação do desenvolvimento é abstrata e deslocada dos processos sociais e culturais, com ausência de dialética.

Para Leontiev (2004), as condições históricas concretas determinam as perspectivas de desenvolvimento do psiquismo humano, contribuindo para a manutenção ou o desaparecimento de traços da consciência humana. Assim, o desenvolvimento do psiquismo depende do modo como a vida se produz, das relações sociais existentes e do lugar que o indivíduo ocupa nessas relações. As estruturas psíquicas são construções sociais e as investigações precisam compreender que o desenvolvimento do coletivo produz as funções individuais, ou seja, o social cria as funções psíquicas superiores. O cérebro humano atual é muito mais complexo do que o do homem neandertal, porque os novos traços humanos produzidos a partir do trabalho e das relações sociais transformaram a estrutura do córtex cerebral.

Duarte (2006) esclarece que a existência de processos de luta entre o natural e social não significa a supressão do natural pelo social. $\mathrm{O}$ autor defende dois pontos da concepção vigotskiana, necessários para se entender a relação natural e social: o trabalho e os processos psíquicos superiores como características essenciais para compreender o homem como ser histórico e social.

O primeiro é a de que Vigotski adotava o pressuposto marxista de que por meio do trabalho o ser humano vem, ao longo da história social, criando o mundo da cultura humana e que o mundo social não pode ser explicado como uma continuação direta das leis que regem os processos biológicos. [...] $\mathrm{O}$ segundo ponto importante da concepção vigotskiana sobre as relações entre o natural e o social é a questão dos processos psíquicos superiores. Para Vigotski, esses processos são de natureza social e formam-se por meio da superação e da 
incorporação dos processos psíquicos elementares, de origem biológica (DUARTE, 2006, p. 196).

Para Vigotski (2010), no desenvolvimento humano existe uma superação dos aspectos biológicos, diferentemente de como ocorre nas outras espécies animais. As pesquisas sobre o desenvolvimento do cérebro nos animais permitem afirmar que, geralmente, as novas edificações acontecem a partir dos níveis do estágio anterior, e que para cada desenvolvimento decisivo biológico existe uma mudança na estrutura e nas funções do sistema nervoso.

Vygotski e Luria (2007), na investigação sobre a distinção entre inteligência prática da criança e do macaco, identificam características especificamente humanas no comportamento infantil. As ações dos macacos são determinadas fundamentalmente por relações físicas, por exemplo a estrutura visual, na criança a experiência social desempenha um papel fundamental. Martins (2013) sintetiza essa discussão apresentando o seguinte postulado: por mais avançado que chegue o comportamento animal com um estágio do intelecto, não ultrapassa os estreitos limites biológicos afetos à adaptação do organismo ao meio. O desenvolvimento do psiquismo animal possibilita o comportamento animal individual e não o comportamento da espécie.

De acordo com Vigotski (2010), o psiquismo humano se institui por meio da atividade social na qual os seres humanos se relacionam com a realidade objetiva, para satisfazer as suas necessidades e para melhor captar e dominar a realidade. O curso da evolução biológica do homem termina antes de começar o desenvolvimento histórico. As tentativas de explicar a forma de pensar do homem não se fixam mais nas particularidades morfofisiológicas transmitidas por hereditariedade, mas no trabalho que inaugura um novo dinamismo de transmissão das conquistas às novas gerações.

Nesse sentido, Leontiev (2004, p. 282) apresenta que “[...] as modificações biológicas hereditárias não determinam o desenvolvimento sócio-histórico do homem e da humanidade". Os seres humanos, pela atividade criadora e produtiva, ou seja, trabalho, conseguem transmitir às gerações as aquisições da evolução. Ao apropriar-se das riquezas produzidas pela humanidade, participando do trabalho, da produção e das atividades sociais, o ser humano desenvolve-se. A fabricação e o uso de instrumentos imbricam no psiquismo humano um processo de consciência do objeto e da ação, e a linguagem faz parte desse processo de o ser humano satisfazer suas necessidades, dentre elas de comunicação com outros seres humanos.

Assim, sua constituição em ser social envolve a transição da história natural dos animais à história social dos homens, marcada pelo trabalho social, pelo emprego dos instrumentos e pelo desenvolvimento da linguagem. No processo de transformação de hominização em humanização a unidade funcional mão-cérebro-linguagem levou ao aperfeiçoamento anátomo-fisiológico do córtex cerebral, permitindo que, com a influência do trabalho e da linguagem, o ser humano saísse de uma condição orgânica para uma condição de ser social. Desse modo, as transformações no psiquismo humano, marcadas pelo trabalho e por novas funções conquistadas pela complexa articulação entre mãocérebro-linguagem, inauguram um processo histórico de desenvolvimento de funções afetivo-cognitivas mais complexo.

[...] o desenvolvimento do trabalho exigiu, e continua a exigir, profundas transformações nas características dos homens. Como atividade coletiva, social, resulta em uma histórica e progressiva complexificação de relações interpessoais e interpsíquicas, determinando que seus executores conquistem graus cada vez mais elevados de autocontrole do comportamento (MARTINS, 2013, p. 47). 
Fica explícita a contribuição da filosofia marxista para a constituição da natureza sócio-histórica do psiquismo e das funções. Sendo assim, as funções psíquicas superiores em Vigotski cumprem um objetivo de explicar o psiquismo humano sem separá-lo do mundo material e das objetivações culturais.

Segundo Martins (2013), Vigotski colocou no centro de seus interesses o processo de desenvolvimento do psiquismo, postulando a tese de que os determinantes do desenvolvimento se encontram na cultura historicamente sistematizada pelo trabalho humano. A complexa trajetória do ser orgânico transformando-se em ser social, no desenvolvimento filogenético, pelo qual a natureza se humaniza e o ser humano se constitui, é característica importante para a compreensão da historicidade. A Psicologia soviética enfatiza a materialidade na constituição do psiquismo, fazendo uma análise da transformação do processo de hominização em processo de humanização. Ocorre um salto ontológico representado pelo trabalho, que diferencia os animais do ser humano. As condições objetivas, asseguradas pelo trabalho como atividade vital, permitiram a transformação de um ser hominizado em um ser humanizado e, portanto, uma mudança na estrutura do psiquismo e nas formações psíquicas superiores.

Se, por um lado, o patrimônio material e ideal se coloca como dado para apropriação, por outro e ao mesmo tempo, é tido como condição imprescindível do processo de transformação de um ser hominizado, isto é, que dispõe de dadas propriedades naturais filogeneticamente formadas, em um ser humanizado, isto é, que se (trans) forma por apropriação da cultura (MARTINS, 2013, p. 271).

A natureza psicológica dos indivíduos também é fruto do conjunto das relações sociais, que se constituem no desenvolvimento humano tanto filogeneticamente como ontogeneticamente. Martins (2013) reconhece a sociedade como constituinte na vida, imanente na formação do psiquismo, mas destaca que é preciso reconhecer que as relações sociais de produção geram subjetividades que expressam, em suas possibilidades e limites, a qualidade do pertencimento social de cada pessoa. Assim, o social é categoria importante para explicar as questões tanto da ontogenia quanto da filogenia.

A palavra social em aplicação no nosso caso tem muitas significações: 1) mais geral - todo o cultural é social; 2) sinal - fora do organismo como instrumento, meio social; 3) todas as funções superiores constituíram-se na filogênese, não biologicamente, mas socialmente; 4) mais grosseira - significação - os mecanismos dela são uma cópia do social. Elas são transferidas para a personalidade, relações interiorizadas da ordem social, base da estrutura social da personalidade. Sua composição, gênese, função (maneira de agir) - em uma palavra, sua natureza - são sociais (VIGOTSKI, 2000, p. 26).

As características da espécie humana foram sendo modificadas historicamente, a nossa constituição como homo sapiens, ou seja, a evolução ao longo de milhares de anos da história humana, constitui-se como profunda relação com os fatores biológicos e sociais. Nesse processo filogenético, a formação das funções psíquicas superiores ocorre com mudanças fisiológicas que vão se transformando no desenvolvimento evolutivo da espécie humana, de forma que o homem, como ser social, possa desenvolver suas características culturais. Os aspectos biológicos e culturais que se entrelaçam no desenvolvimento filogenético e ontogenético compõem um processo único do desenvolvimento humano.

Vigotski (2010), ao considerar as raízes biológicas/orgânicas do desenvolvimento cultural, pretendia apresentar a existência de uma síntese superior, que estabelecesse leis fundamentais da estrutura e do desenvolvimento das funções psíquicas superiores. A cultura, além de criar formas específicas de comportamento humano, é capaz de modificar 
o funcionamento das funções psíquicas, proporcionando às funções psíquicas um caráter peculiar que é produzido simultaneamente e conjuntamente com o processo de maturação orgânica. O desenvolvimento histórico do homem social transforma os modos de procedimento do comportamento humano, desenvolve e cria novas formas culturais específicas.

No ser humano, o desenvolvimento das funções psíquicas superiores gera um novo nível de desenvolvimento do sistema nervoso central. Existe assim uma dependência direta das formas superiores com o desenvolvimento do sistema nervoso e do cérebro, logo seria impossível o desenvolvimento das funções psíquicas superiores sem o desenvolvimento do cérebro humano. No entanto, as explicações das funções psíquicas superiores não estão no córtex, mas nos estímulos que dirigem a atividade do cérebro, não sendo, pois, estruturas naturais, mas construções. É preciso, portanto, esclarecer como ocorre esse processo de desenvolvimento das funções psíquicas superiores na relação entre o biológico (estrutura cerebral e sistema nervoso central) e o cultural.

Para Vigotski (2010), na análise sobre a história do cérebro era preciso considerar duas leis. Primeiro, considerando que no desenvolvimento dos centros superiores os inferiores se conservam como instâncias subordinadas ao desenvolvimento das superiores e continuam funcionando unidos, de maneira que não se pode diferenciá-los separadamente. A segunda lei do desenvolvimento cerebral consiste no fato de que os centros inferiores não mantêm o funcionamento da mesma forma, incorporando parte essencial de suas funções nos novos centros. Existe, portanto, uma superação dos novos níveis que nascem sobre o velho, mas, ao mesmo tempo, existe uma conservação de partes anteriores. Como pode-se observar, essa concepção está de acordo com o pensamento dialético de suprassunção, que supera conservando.

De acordo com Vygotski e Luria (2007), a forma singular das funções psíquicas superiores surge historicamente de forma mediada, elevando a conduta das formas elementares, presente nos animais, às condutas complexas do ser humano civilizado, em oposição às concepções espiritualistas e naturalistas. A partir dessa premissa sobre a história social do desenvolvimento das funções psíquicas superiores, Vigotski (2010) empreendeu um novo método de análise, capaz de capturar essa dialética entre as funções psíquicas superiores e elementares, além da importância dos processos de mediação, conforme veremos a seguir.

\section{A mediação no desenvolvimento das funções psicológicas superiores}

Para compreender o problema de construção e gênese das funções psíquicas superiores é preciso considerá-las a partir das leis funcionais, estruturais e genéticas. No capítulo Análises das funções psíquicas superiores, Vigotski (2010) apresenta três características determinantes para apoiar suas investigações e a análise das formas superiores de comportamento - análise psicológica no processo e não apenas no objeto, buscando demonstrar os nexos dinâmico-causais, as relações com outros processos que determinam o desenvolvimento. Para além de uma análise descritiva e explicativa, um método genéticocausal contempla os processos de desenvolvimento do estado atual a fim de que, mediante a investigação objetiva do processo em seu conjunto, consiga ir além da aparência externa ou interna, buscando captar as condições que marcam o ponto final, mas também todo o desenvolvimento desse processo. Essa é a interpretação de uma forma qualitativamente peculiar do processo de desenvolvimento psíquico superior.

Vygotski e Luria (2007) revelam que os métodos de investigação dos mecanismos psíquicos de reflexos simples são diferentes dos processos psíquicos mais complexos, visto que a aparição de formações qualitativamente novas e as inter-relações entre as funções psíquicas não poderiam ser ignoradas. "A singularidade da gênese, da estrutura e o 
funcionamento dos processos psíquicos superiores permaneciam assim muito longe do alcance da metodologia da psicologia elementar" (VYGOTSKI; LURIA 2007, p.72).

Ao explicar a análise que decompõe em unidades um todo complexo, Vigotski (2018, p. 40) identifica dois traços opostos: “A análise que decompõe em elementos é definida pelo fato de o elemento não conter propriedade do todo. Já a unidade é definida pelo fato de que é a parte de um todo que contém, mesmo que de forma embrionária, todas as características fundamentais próprias do todo". Análises que decompõem o todo complexo em seus constituintes perdem de vista as relações essenciais que fazem deles componentes de um todo específico.

$\mathrm{Na}$ tentativa de compreender os fenômenos e os processos psíquicos em suas complexidades, Vigotski propôs outro tipo de análise: o método da unidade, em que o todo pudesse ser segmentado em unidades. Assim, Vigotski (2009, p. 8) define a unidade como "um produto da análise que, diferente dos elementos, possui todas as propriedades que são inerentes ao todo e, concomitantemente, são partes vivas e indecomponíveis dessa unidade". Assim, uma característica fundamental da unidade consiste no fato de a análise destacar as partes que não perderam a propriedade do todo.

Para Martins (2013), a existência desses sistemas funcionais cerebrais em relação com comportamentos humanos precisa ser compreendida apenas por análises que capturem as conexões e relações interfuncionais da complexidade do psiquismo humano. E continua essa reflexão a partir do princípio da totalidade, em que nem o cérebro nem o psiquismo podem ser reduzidos às partes, pois representam uma particularidade.

A autora destaca que à medida em que Vigotski se dedicou a estudar as interdependências entre as funções psicológicas pelo método de análise por unidade, encontrou, na significação do signo, um elemento essencial para a compreensão do psiquismo como sistema interfuncional. $\mathrm{O}$ emprego dos signos articula e rearticula as funções psíquicas como um todo. De acordo com Vigotski (2010), entre o estímulo e a reação do sujeito aparece um novo membro intermediário a toda operação, que se constitui como um ato mediado. A existência de um estímulo intermediário, chamado de signo, modifica a própria estrutura de todo o processo. Além da mediação de signos, Vigostski (2010) considera a mediação de instrumentos, conforme é apresentado no decorrer do texto.

$\mathrm{Na}$ estrutura superior, o signo é o modo de seu desempenho, sendo determinante funcional de todo o processo.

Os signos e os significados mobilizados nas ações realizadas pelos indivíduos, em sua existência concreta, engendram as rearticulações interfuncionais. (...) $O$ uso de signos determina rupturas no modo de operar já instalado de uma função específica e, ao fazê-lo, modifica suas articulações com outras funções, inaugurando novas formas de manifestação psíquica (MARTINS, 2013, p. 67).

A autora compreende que o emprego dos signos, na teoria vigotskiana, é um "divisor de águas" entre as expressões naturais e culturais e, para isso, apresenta elementos para a compreensão do enfoque sistêmico do desenvolvimento do psiquismo de Vigotski e das funções psíquicas superiores. Nesse sentido, o desenvolvimento do psiquismo humano, a dimensão interfuncional, depende das apropriações culturais e das condições históricas que os indivíduos tiveram a possibilidade de desenvolver. Essa compreensão do psiquismo como sistema interfuncional substitui o enfoque analítico pelo enfoque integral ou estrutural.

Para Vigotski (2010), o desenvolvimento das funções psíquicas superiores nos indivíduos ocorre em um processo de transformação mediado pela apropriação dos signos da cultura, que intermediarão a relação entre os processos naturais e o comportamento humano. Tanto os signos como os instrumentos são atividades mediadoras que permitem 
aos objetos uma influência recíproca, da qual depende a consecução do seu objetivo. A mediação ultrapassa, portanto, a relação aparente entre as coisas, penetrando na esfera das intervinculações entre suas propriedades essenciais. Ao internalizar as formas culturais de comportamento existe uma reconstrução da atividade psíquica baseada na operação com signos. Sendo assim, os processos psíquicos são culturalmente reconstruídos e desenvolvidos a partir de uma nova estrutura psicológica.

Vigotski (2010) explicita semelhança entre o uso do signo e do instrumento de trabalho para a atividade psicológica enquanto função mediadora, mas também diferenças básicas e elos reais existentes entre esses conceitos. Tanto signo quanto instrumento podem afetar o comportamento humano, embora isso aconteça de forma diferente. Instrumento é uma atividade humana externa, que existe para dominar a natureza, gerando uma modificação do objeto. Já o signo constitui uma atividade interna, dirigida para o próprio controle do indivíduo, que em nada modifica o objeto da operação psicológica.

Para Martins (2013, p. 46), o conceito de mediação de Vigotski só pode ser compreendido pela relação com a filosofia marxista, para não ser reduzido à ponte, mas meio das coisas - "A mediação é a interposição que provoca transformação, encerra intencionalidade socialmente construída e promove desenvolvimento, enfim, uma condição externa que, internalizada, potencializa o ato de trabalho, seja ele prático ou teórico". Então, para se entender o papel dos signos na conduta humana, Vigotski refere-se à função instrumental que este assume.

Martins (2013) sintetiza que a relação lógica entre ferramenta e signo não é uma relação de identidade genética ou funcional, mas também não é casual. $O$ instrumento técnico se interpõe entre a atividade do homem e o objeto externo e transforma o objeto. O signo, como instrumento psicológico, orienta-se em direção ao psiquismo e ao comportamento e transforma o sujeito.

De acordo com a autora, o papel do trabalho e o papel da apropriação dos signos no desenvolvimento do psiquismo humano são categorias presentes na Teoria HistóricoCultural, que explicam as transformações do desenvolvimento intelectual dos animais para o ser humano. Signo e instrumento estão ligados tanto na filogênese como na ontogênese, visto que, ao controlar a natureza, o ser humano controla o seu próprio comportamento. $\mathrm{Ou}$ seja, as alterações que o homem provoca na natureza mudam a própria natureza humana. A discussão do trabalho realizada por Marx apresenta exatamente essa ideia:

Trabalho é o processo de que participam o homem e a natureza, processo em que o ser humano, com sua própria ação, impulsiona, regula e controla seu intercâmbio material com a natureza. [...] Atuando sobre a natureza externa e modificando-a, ao mesmo tempo modifica sua própria natureza (MARX, 2011, p. 211).

Se o trabalho permitiu ao homem dominar a natureza, o emprego dos signos permitiu-lhe dominar a si mesmo. Nesse processo de interação ativa com o meio ambiente, constituído pela influência cultural, ocorre a transformação de processos neuropsicológicos naturais em processos complexos. $\mathrm{O}$ ser humano ultrapassa então os limites dados pelo sistema orgânico, inaugurando as possibilidades sociais de seu desenvolvimento. Os instrumentos funcionam como uma ferramenta exterior e os signos como interior. Nessa relação, entre interno e externo em um processo dialético entre as funções psíquicas superiores e inferiores, Vigotski (2010) retoma a expressão da categoria de suprassunção, isto é, superar conservando - as formas inferiores não se aniquilam quando se incluem na superior, continuam existindo nela como instâncias editadas.

A estrutura superior é a forma especial de organização de todo o processo, que se constrói graças à introdução na situação de determinados estímulos artificiais que cumprem o papel de signos. O papel de funcionamento distinto, dos estímulos e de suas conexões 
recíprocas, serve de base para os nexos e as relações que constituem o próprio processo. Assim, à medida que os signos produzidos pelo conjunto dos seres humanos são cada vez mais complexos, as funções psíquicas superiores também vão adquirindo graus de complexidade. O domínio de cada indivíduo em relação aos signos produzidos socialmente influencia o desenvolvimento do psiquismo humano.

Relembra-se que o conceito de estrutura está presente desde o começo da história do desenvolvimento cultural da criança, logo as peculiaridades biológicas da psique constituem as estruturas primitivas ou inferiores que são o ponto de partida de todo o processo de desenvolvimento das funções psíquicas superiores. Dessa forma, é impossível o estudo das formas superiores de comportamento sem as inferiores, mas a existência das inferiores não esgota as possibilidades da superior.

Segundo Vygotski; Luria (2007), a gênese das formas mais complexas dos processos psíquicos superiores é revelada nos experimentos que mostram os meios auxiliares de conduta, desempenhando papéis de organização da própria conduta. Ao reconhecer a importância do signo no desenvolvimento das funções psíquicas superiores, os autores apresentam, como uma consequência lógica, a inclusão de novas formas de conduta constituídas ao longo do processo de desenvolvimento. Relaciona-as em demonstração da unidade entre as formas psicológicas externas, sociocultural, da criança com seus processos internos do psiquismo.

\begin{abstract}
Devemos incluir no sistema de categoria psicológicas aquelas formas psicológicas externas de atividade - como a fala, a leitura, a escrita, o cálculo e o desenho - que até agora se haviam considerados estranhos e complementares aos processos psíquicos internos, desde o ponto de vista que estamos defendendo é preciso incluí-las no sistema mesmo das funções psíquicas superiores com mesmo direto que o resto dos processos superiores (VYGOTSKI; LURIA, 2007, p. 50).
\end{abstract}

Todas as funções psíquicas superiores são relações sociais interiorizadas, portanto não são simples produtos biológicos ou apenas aquisições da história do desenvolvimento filogenético, são o fundamento da estrutura social da personalidade. Nesse contexto, Vigotski (2010) retoma a tese marxista na qual o autor faz comparação com a natureza psíquica do homem como um conjunto de relações sociais transferidas ao interior e convertidas em funções da personalidade, bem como formas de sua estrutura. Assim, a definição de interiorização em Vigotski, não sendo um processo mecânico da atividade externa que passa a compor a atividade interna, ratifica a relação entre o desenvolvimento do psiquismo e a realidade social.

É no processo de interiorização que os signos se convertem em instrumentos fundamentais da atividade mental interna, da atividade intelectual. Os signos, por sua vez, apenas se estruturam nas interações sociais, na cultura, e são os meios das atividades internas, dirigidos, inclusive, para o controle do próprio indivíduo (MARTINS, 2011, p. 70).

"Cada uma das funções psíquicas superiores foi anteriormente uma forma distintiva da cooperação psíquica e somente posteriormente se converte em modo individual de comportamento" (VYGOTSKI; LURIA, 2007, p. 51). Assim, no desenvolvimento da criança não existe uma hierarquização dos processos elementares e superiores, na qual o biológico antecede o desenvolvimento cultural. No desenvolvimento cultural a interrelação do adulto com a criança é a força motriz básica do desenvolvimento. Esse aspecto do desenvolvimento das funções psíquicas superiores na periodização do desenvolvimento humano será discorrido a seguir. 


\section{O desenvolvimento das funções psicológicas superiores e a periodização}

Procuraremos demonstrar a compreensão do desenvolvimento das funções psíquicas superiores na criança, considerando as análises de como foram produzidas no gênero humano e o processo em cada período do desenvolvimento relacionado às condições sociais.

Vigotski (2010) apresenta crítica ao enfoque naturalista predominante na Psicologia infantil, onde pressupõe o desenvolvimento das funções psíquicas como processo linear e etapista. Desse ponto de vista, o conceito de desenvolvimento psíquico da criança, nas pesquisas realizadas até por volta de 1930, era limitado ao desenvolvimento biológico das funções elementares, que transcorriam em direta dependência da maturação cerebral como função de maturação orgânica da criança.

Segundo o autor, essas teorias estudavam a criança e o desenvolvimento de suas funções psíquicas superiores abstratamente, à margem de seu meio social e cultural, assim como as formas de pensamento lógico das concepções e ideias sobre a causalidade que predominam nesse meio. $\mathrm{O}$ autor critica as teorias que compreendem o desenvolvimento da criança de forma estereotipada, comparando o desenvolvimento humano como simples adaptação ao meio circundante, a exemplo de outras espécies animais. Também censura as teorias que explicam as formas superiores de comportamento da mesma forma que explicam as inferiores. Era preciso conhecer então as peculiaridades fundamentais do desenvolvimento infantil em entrelaçamento com os processos de desenvolvimento cultural e biológico, conforme apresentamos anteriormente neste capítulo.

Ao analisar as funções psíquicas superiores em um processo de entrelaçamento entre os aspectos naturais e culturais, Vigotski (2010) estabelece quatro teses. A primeira é o reconhecimento das bases naturais das formas culturais de comportamento, na qual "a cultura não cria nada, tão somente modifica as amplitudes naturais em concordância com os objetivos do homem" (VIGOTSKI, 2010, p. 105).

A segunda tese, de acordo com o desenvolvimento de crianças anormais, afirma que uma ou algumas funções podem substituir as outras no processo do desenvolvimento cultural da criança. A terceira assevera que a base estrutural das formas culturais do comportamento é a atividade mediadora, a utilização de signo externo como meio para o desenvolvimento interior da conduta. Por isso, o signo tem importância primordial no desenvolvimento cultural. Já a última tese apresenta considerações sobre o domínio da própria conduta, podendo diferenciar os níveis de desenvolvimento de uma ou outra função dos níveis de desenvolvimento desta função.

No capítulo Génesis de las funciones psíquicas superiores, Vigotski (2010) retoma as considerações sobre a peculiaridade do processo de desenvolvimento das formas superiores de conduta e a necessidade de esclarecer o conceito de desenvolvimento para além dos aspectos quantitativos. As investigações científicas tinham então o desafio de descobrir o complexo processo de desenvolvimento em toda a sua plenitude real e captar todas as mudanças e transformações qualitativas que modificam a conduta e a personalidade da criança, constituindo-se em ser sociocultural.

Vygotski e Luria (2007) também sistematizam leis fundamentais do desenvolvimento das funções psíquicas superiores. A primeira elucida que a história do desenvolvimento das funções psíquicas superiores não significa uma continuidade direta, com aperfeiçoamento de uma função elementar correspondente, mas existe uma mudança radical do desenvolvimento e um avanço completamente novo, em que cada nova função superior constitui uma neoformação concreta.

$\mathrm{Na}$ segunda lei, as funções psíquicas superiores não se sobrepõem aos processos elementares, mas constituem novos sistemas psíquicos que incluem um complexo tecido de 
funções elementares, os quais, ao serem incorporados ao novo sistema, começam a atuar a partir das novas leis. Cada função psíquica superior, conforme uma unidade de uma ordem mais alta, está determinada, fundamentalmente, pela particular combinação entre uma série de funções mais elementares e uma nova unidade global.

$\mathrm{Na}$ discussão sobre a história do desenvolvimento cultural das crianças, Vigotski (2010) apresenta que é na relação com o outro que passamos a nos individuar, e isso não apenas no que se refere à personalidade, mas ao conjunto de cada função psíquica isolada. A partir dessa relação é que se pode afirmar a correlação entre as funções psíquicas internas e externas, compreendendo externo como social. Portanto, toda função psíquica superior foi externa, ou seja, social, antes de ser interna.

Desse modo, Vigotski (2010) formula a lei genética geral do desenvolvimento cultural, na qual toda função do desenvolvimento cultural da criança aparece duas vezes, em dois planos: primeiro no plano social e depois no psicológico, primeiro entre os homens, como categoria interpsíquica, e logo no interior da criança, como categoria intrapsíquica. Essa lei também é denominada de sociogênese das formas superiores de comportamento.

De modo que o signo opera inicialmente na conduta infantil como um meio de relação social, como uma função interpsíquica. Posteriormente se converte em um meio pelo que a criança controla sua própria conduta de modo que o signo simplesmente transfere ao interior da personalidade atitude social em direção ao sujeito (VYGOTSKI; LURIA, 2007, p. 51).

De acordo com Vygotski; Luria (2007, p. 51), “o comportamento humano é produto do desenvolvimento do sistema mais amplo de vínculos e relações sociais, de forma coletiva de conduta e cooperação social”. As funções psíquicas superiores apresentam-se primeiramente como forma distintiva de cooperação psíquica, e posteriormente convertem-se em comportamento individual. A síntese da origem das formas superiores de comportamento consciente encontra-se nas relações sociais que o indivíduo mantém com o mundo exterior.

Vigotski (2006) apresenta as formações qualitativamente novas, com ritmo próprio e que se desenvolvem sempre por mediações. Essas neoformações promovem viragem e giros no curso do desenvolvimento, proporcionando bases para determinar os principais períodos de formação da personalidade da criança. Assim, novas formações provocam transformações na personalidade do indivíduo, ou seja, ocorrem mudanças na situação social, nas funções psíquicas, provocando modificação na compreensão de si mesmo e do mundo que o cerca, que também possibilitará uma nova atuação na realidade.

Não é uma postura passiva, mas um agir ativo que permite complexificação do desenvolvimento, como ocorre na percepção sobre influência da cultura, por exemplo. Mediadas por outro ser humano, as características sociais do objeto podem ser percebidas pela criança, em uma procura ativa das informações do objeto, distinguindo os aspectos essenciais dos secundários, comparando com outros objetos.

Martins (2013, p. 29), baseada nos estudos dos filósofos Iliénkov e Kopnin, afirma que "[...] a imagem subjetiva não é uma cópia mecânica do real, não se institui unilateralmente no contato imediato com dado objeto, produzindo-se na relação ativa entre sujeito e objeto". A partir do pressuposto marxista, que reconhece o caráter ativo do pensamento humano, entendemos que o pensamento está condicionado pela atividade que liga o sujeito ao objeto e à possibilidade de representação. As imagens mentais ultrapassam, pois, a singularidade do objetivo, representando traços universais que serão a raiz da formação de conceito e da própria consciência humana. "Portanto, se há um trânsito dinâmico e condicionado no processo de conversão do objeto da natureza em objeto da 
consciência (imagem/conceito), apenas a objetivação prática do segundo poderá afirmar a sua veracidade" (MARTINS, 2013, p. 9).

Para Vigotski (2018), só é possível apresentar algumas regularidades que orientam o desenvolvimento psíquico da criança considerando a influência do meio no desenvolvimento em todos os seus aspectos. Assim, as mudanças no psiquismo, determinadas pelas relações sociais, produzem alterações nas funções psíquicas, modificando as correlações entre elas, "[...] pois existe uma especificidade no sistema de relações entre as funções para cada etapa etária" (VIGOTSKI, 2018, p. 95). Em cada idade o desenvolvimento da consciência da criança apresenta um elemento novo, fruto das mudanças nas atividades, no psiquismo e nas relações sociais, ou seja, na relação com meio a vida interna e externa se transformam.

É importante destacarmos que o conceito "neoformações, ou sínteses complexas das funções psíquicas, emergem da situação social em que a criança está inserida, a qual lhe exige determinadas reações. Tais exigências, por sua vez, mobilizam funções ainda não completamente desenvolvidas" (TULESKI; EIDT, 2016, p. 53). Dessa forma, as mudanças e transformações qualitativas de neoformações, ocorrem por entrelaçamento de processos evolutivos e involutivos, com interseção de fatores internos e externos, em um processo complexo de superação e adaptação.

De acordo com Vigotski (2006) existem idades relativamente estáveis, em que o desenvolvimento ocorre lentamente, que vão acumulando mudanças até um certo limite, que se manifestam mais tarde em repentinas formações qualitativamente distintas em cada idade. No entanto, existem pontos de viragem no desenvolvimento infantil, denominados como crise. "A existência de um ponto culminante da crise é uma característica de todas as idades críticas, diferenciando-a sensivelmente das etapas estáveis do desenvolvimento infantil" (VIGOTSKI, 2006, p. 256). Existe influência das condições internas e externas sobre a própria crise, que geram a continuidade do processo do desenvolvimento, com características distintas nas diferentes crianças, a depender das relações sociais.

Assim, a periodização das idades pode ser apresentada com intervalos de estabilidade e crises do seguinte modo: crise pós-natal, primeiro ano (dois meses a um ano); crise do primeiro ano, primeira infância (um ano a três anos); crise dos três anos, idade préescolar (três anos a sete anos); crise dos sete anos, idade escolar (oito anos a doze anos); crise dos treze anos, puberdade (catorze a dezoito anos); crise dos dezessete anos.

A partir da Teoria Histórico-Cultural, as crises no processo de periodização do desenvolvimento do psiquismo têm aspectos negativos e positivos, que precisam ser aprofundados em perspectiva dialética, onde a passagem de um estágio a outro não ocorre por vias evolutivas, mas sim revolucionárias. Para Leontiev (2004), as crises podem ser superadas a partir de um processo educativo racionalmente orientado, conduzido para considerar as estruturas novas que aparecem no período de transição de um estágio para outro. Nessa perspectiva, é preciso estudar a dinâmica das idades e a situação social que influencia nas novas estruturas do psiquismo, compreender a origem de novas formações e as consequências advindas das novas estruturas, bem como observar as mudanças internas e de comportamento.

Para Tuleski e Eidt (2016), o movimento dialético que caracteriza o desenvolvimento infantil, que se inicia no nascimento e na inserção da criança à uma determinada sociedade, cultura e classe social, ocorre numa espiral dialética, envolvendo avanços e recuos, saltos e paralisações. Nesse processo estão presentes as neoformações (estrutura central de cada idade), a reestruturação da situação social de desenvolvimento (idades críticas) e a situação social de desenvolvimento como ponto de partida (relações estabelecidas com a criança em cada período).

Vigotski (2006) destaca teses gerais do processo do desenvolvimento de cada período de idade, que reconhecem a complexidade de sua organização e composição. A 
estrutura refere-se a formações globais não compostas pela soma das partes, como uma espécie de agregados, mas pela multiplicidade dos processos parciais que o integram e constituem um todo único, que por si mesmas determinam o destino e o significado de cada parte que as integra.

Para o autor, em cada período da idade existe uma nova formação central, que guia todo o desenvolvimento que caracteriza a reorganização de toda a personalidade da criança sobre uma base nova. Além da formação central existem outras novas formações, as parciais, que se agrupam a ela, assim como as formações remanescentes dos períodos anteriores. Outra tese defendida pelo autor é a de que em cada idade a situação social do desenvolvimento é o ponto de partida para todas as mudanças dinâmicas que se produzem no desenvolvimento, capaz de determinar e regular todo o modo de vida da criança ou sua existência social.

Mediante essas premissas, tentaremos deixar mais clara a complexidade da periodização do desenvolvimento do psiquismo em sua relação com as condições histórico-sociais concretas, entendendo a aprendizagem como processo ativo de participação do sujeito na relação com o meio, promovendo o desenvolvimento. A compreensão sobre desenvolvimento só é possível na unidade contraditória com a aprendizagem, na qual a nova aprendizagem se estrutura sobre a base das anteriores, determinando sua reestruturação e novas relações internas entre si, constituindo mudanças decisivas para a complexificação psíquica, que resultam na promoção do domínio da própria conduta.

Nesse texto tomaremos como base o sistema de periodização elaborado por Vygotski (1996), apresentando a dinâmica no processo de desenvolvimento de novas formações psíquicas. Ou seja, explicitando algumas mudanças ocorridas nas idades infantis na relação com as determinações sociais e destacando a importância da cultura nas transformações das funções elementares, tornando-as superiores..$^{3}$

$\mathrm{Na}$ criança recém-nascida, que não conhece nada sobre o mundo, ainda predominam as funções psíquicas elementares e as estruturas biológicas. Na consciência do bebê existe o germe de todas as funções, mas não podem funcionar isoladamente. Isto é, "[...] no início não há o desenvolvimento de certas funções em geral; existe apenas a consciência como um todo indiferenciado e, pelo visto, o próprio desenvolvimento consiste na diferenciação de certas funções, que, como veremos, ocorre em determinadas idades" (VIGOTSKI, 2018, p. 98). A apropriação da cultura, desde as sensações ligadas aos sentidos, como paladar, olfato, tato, incluindo as sensações de carinho e afeto, precisam ser conhecidas e memorizadas pelo bebê.

Segundo Vigotski (2018), o reconhecimento da mãe, dos objetos, vai demonstrando a capacidade de o bebê assimilar e recordar os aspectos do meio, a partir dos estímulos dados pela cultura no processo de convívio do adulto com o recém-nascido. Para capturar às características externas ocorre uma intensa memorização do bebê, que, contraditoriamente, ao mesmo tempo não consegue conservar as recordações dessa idade. No entanto, a memorização não está separada das emoções, da fome do instinto, da saciedade, não está separada da percepção. "A memória da criança na primeira infância age apenas quando e enquanto puder participar da atividade de percepção." (VIGOTSKI, 2018, p. 99).

De acordo com Vygotski e Luria (2007), na criança pequena o processo de desenvolvimento depende do campo sensorial, por isso têm a percepção como mediadora

\footnotetext{
3 Reconhecemos que Leontiev (2004) também investigou a influência da atividade humana no desenvolvimento do psiquismo e distinguiu uma periodização com base no conceito de atividade dominante. Segundo o autor atividade dominante são aquelas atividades que influenciam de maneira "mais determinante" no desenvolvimento do psiquismo em certos períodos da vida. É por meio dela que o indivíduo se apropria do mundo objetivo e delimita continuamente sua personalidade. No entanto, para a discussão neste texto nos basearemos na discussão que Vigotski faz da periodização do desenvolvimento humano e das neoformações presentes em cada período.
} 
principal do incremento das unidades psíquicas complexas. Assim, nesse momento inicial, a percepção afetiva ocupa função dominante, isto é, está no centro, determinando todas as outras atividades da consciência. Podemos destacar outras funções psíquicas nesse período, para elucidar que estão todas submetidas à percepção. Por exemplo, o pensamento reduzido ao campo concreto-visual, ou seja, a ação racional direcionada à relação dos objetos percebidos visualmente. Como já expusemos anteriormente, o psiquismo humano é reconhecido pelas relações interfuncionais entre as funções, e esse processo é caminho da reestruturação do sistema antigo e de transformação de um novo sistema.

Relembramos que o desenvolvimento do bebê é marcado por muitas transformações. Vigotski (2006) divide o primeiro ano em estágio passivo, interesse receptivo, interesse ativo, sendo que neste último há a utilização de ferramenta e o emprego de palavra para expressar o desejo. A aparição da linguagem marca a crise do primeiro ano, primeiramente como a criança relaciona a palavra com significados, estabelecendo nexos entre os objetos e as palavras. O autor destaca a contradição entre sua máxima sociabilidade e as mínimas possibilidades de comunicação.

Para Vygotski e Luria (2007), a internalização e a utilização de um instrumento psicológico (signos) na organização da vida social dos sujeitos, promoverá e possibilitará intensas transformações nas operações do psiquismo. Portanto, a relevância do processo cultural de aquisição da fala possibilita uma complexificação da imagem subjetiva da realidade objetiva e, concomitantemente, das suas relações sociais. $O$ entrelaçamento da linguagem com os processos das outras funções psíquicas superiores forma sínteses novas e complexas e reestruturam os processos sobre uma base nova.

Assim, para Vigotski (2016), os aspectos da personalidade da criança não se modificam no transcorrer do desenvolvimento de forma isolada. Por isso, que cada neoformação nas diferentes faixas etárias contribui para as mudanças no processo do desenvolvimento como um todo, reorganizando toda a personalidade da criança a partir dessa base nova. É uma relação dinâmica entre o todo e a parte, de mudanças no desenvolvimento. "Na passagem de uma idade para outra, muda, em primeiro lugar, o sistema de relação entre as funções, e o desenvolvimento de cada função em separado depende do sistema em que ela se desenvolve" (VIGOTSKI, 2018, p. 95).

$\mathrm{Na}$ primeira infância (crianças de um ano a três anos), as novas relações da criança com o meio ocorrem baseadas no desenvolvimento da linguagem como meio de comunicação. Assim, a criança consegue apreender os aspectos semânticos, surgindo as generalizações no domínio da linguagem. No início as generalizações são sincréticas, relacionadas com a situação real, tendo dependência da imagem visual direta, mas, no processo de abstração e generalização, estas se desenvolvem, ampliando os nexos e conexões com relação aos objetos. "Graças ao elo a abstração resulta enriquecida, isto é, na palavra o número de vínculos e representações do objeto é maior que a simples percepção do objeto" (VIGOTSKI, 2006, p. 360).

Esse processo de generalização dos conceitos, que constitui linguagem e pensamento e requalifica todas as outras funções. Por exemplo, pela apropriação da linguagem avança o mundo perceptível, possibilitando a criança agir sobre os objetos em sua ausência, para além do que está no campo visual ou do alcance da manipulação. Assim, é importante salientar que o adulto tem um papel fundamental na contribuição de a criança passar a perceber a relação entre as palavras e a realidade.

Como estamos tentando demonstrar neste texto, a qualidade de função dominante que cada função exerce em determinada idade, produz, em certa medida, mudança toda a consciência na atividade. Por exemplo, os acontecimentos principais e decisivos que determinam o domínio da fala se desenvolvem culturalmente entre um ano e três anos, e provocam que este seja o período de predominância do desenvolvimento da linguagem. $\mathrm{Ou}$ seja, torna-se predominante quando se diferencia suficientemente pela primeira vez do 
restante da consciência, e apresenta-se na máxima condição de contribuir para o desenvolvimento. As relações estabelecidas nesse período continuam no próximo, sendo incorporadas nas novas conexões.

Assim, a crise dos três anos, segundo Vigotski (2006), é marcada por modificações nas relações sociais, que se ampliam do entorno da família para outras relações. Com as mudanças na esfera afetiva e volitiva, a criança se vê imersa em uma série de conflitos internos e externos que podem apresentar sintomas negativos da crise, como desobediência, teimosia e rebeldia. Mas também representa a emancipação, produzindo mudanças da atividade social da criança frente ao entorno e ao prestígio dos pais, ou seja, uma maior autonomia da criança, que passa a negar a ajuda do outro para realizar algumas atividades, como comer e vestir-se.

Para Vigotski (2018), a hierarquia entre as funções demonstra a complexidade do desenvolvimento do psiquismo. Inicialmente, quando a percepção era a única função dominante, não tinha nenhuma outra função predominante no desenvolvimento do psiquismo, esta possibilitou várias relações interfuncionais, que serão incorporadas nas idades posteriores. "Graças à predominância em cada etapa etária, surge, para uma certa idade, um sistema específico de relações interfuncionais que nunca são iguais para funções diferentes" (VIGOTSKI, 2018, p. 102).

Dessa maneira, na idade pré-escolar a percepção não se descola de lugar para que o lugar passe a ser ocupado pela memória, ocorre uma complexificação. "O sistema antigo se transforma de tal modo que a memória, antes de tudo, passa a dominar a percepção, começa a se ligar a ela e, por meio desse centro, reestrutura o resto do sistema" (VIGOTSKI, 2018, p. 108). Dessa forma, com o desenvolvimento das idades os processos psíquicos vão se complexificando. $\mathrm{Na}$ idade escolar duas funções diferenciadas, percepção e memória, que provocaram subordinações a elas, levam a novas diferenciações nos sistemas.

Vigotski (2016) sintetiza a crise dos sete anos relacionando-a com a entrada da criança no contexto escolar, portanto um momento de transição do pré-escolar para o escolar. É marcada pela perda da espontaneidade infantil e a incorporação de um comportamento, o fator intelectual. Além disso, a situação social provoca no desenvolvimento o interesse por estudo, conhecimento e necessidade de leitura e escrita. Há também uma discrepância entre a situação objetiva da criança e a posição interna, porque torna-se capaz de reconhecer suas próprias vivências e afetos para conseguir expressar os sentimentos internos, comunicando-os ao outro. Surge então a percepção e a consciência dos processos vividos.

$\mathrm{Na}$ adolescência predomina um complexo sistema hierárquico no processo do desenvolvimento das funções psíquicas superiores, no qual a função central é o desenvolvimento do pensamento, a função de formação de conceitos. "Todas as outras funções se unem a essa nova formação, integram com ela uma síntese complexa, se intelectualizam, se reorganizam sobre a base do pensamento em conceitos" (VIGOTSKI, 2006, p. 117).

Objetivamos, mesmo de forma breve, demonstrar que a dinâmica do desenvolvimento infantil está relacionada à relação indivíduo-sociedade. Assim, nos períodos críticos é difícil educar a criança, pois nem sempre o processo educativo acompanha as mudanças repentinas em sua personalidade, conforme afirma Vigotski (2006). Por isso, tentamos a todo momento destacar que as condições histórico-sociais concretas são um determinante no desenvolvimento das funções psíquicas como um todo. 


\section{Considerações finais}

Ao tentar descrever e explicar as funções psíquicas superiores, a partir de uma relação de unidade entre os processos psíquicos e as funções neurológicas e fisiológicas ligadas ao cérebro humano, Vigotski desenvolveu a Psicologia dialética. "A psicologia dialética consiste precisamente em descobrir a conexão significativa entre as partes e $\mathrm{O}$ todo, em saber considerar o processo psíquico em conexão orgânica nos limites de um processo integral mais complexo" (VIGOTSKI, 2004, p. 149). Portanto, também nessa relação da totalidade, a compreensão das funções psíquicas superiores é feita a partir da discussão do gênero humano e do desenvolvimento da criança. O processo psicológico é, pois, um fenômeno dialético que é preciso compreender como ocorre a atividade externa que, desde sua gênese, contém componentes psíquicos.

As investigações sobre a estrutura, a gênese e o desenvolvimento das funções psíquicas superiores possibilitaram descobertas fundamentais sobre a complexidade da estrutura psíquica, tendo como ponto de partida as relações sociais. Dentre elas, destacamos o salto qualitativo do psiquismo humano tendo o emprego dos signos como mediação fundamental, que regulam e explicam o comportamento humano; e a internalização dos signos como categoria central no desenvolvimento das funções psíquicas superiores, possibilitando transformações significativas do psiquismo como sistema funcional e construção das atividades culturais humanas. No caso do processo de escolarização, a apropriação dos conhecimentos científicos provocará o desenvolvimento das funções psicológicas superiores provocando transformação na forma e no conteúdo do psiquismo.

Em síntese, na análise do psiquismo humano no contexto da Teoria HistóricoCultural existem três elementos fundamentais para se compreender a temática à luz das leis históricas do desenvolvimento: as funções psíquicas superiores, o desenvolvimento cultural da conduta ou do comportamento e o domínio dos próprios processos do comportamento. Dessa forma, a compreensão da peculiaridade da criança em cada período do desenvolvimento permite capturar o processo dialético e complexo que envolve as mudanças qualitativas das funções psíquicas superiores, por um entrelaçamento complexo de evolução e involuções e cruzamento de fatores externos e internos na dinâmica das idades.

Por fim, compreender a análise do desenvolvimento do psiquismo condicionada à análise das condições objetivas evita a naturalização do desenvolvimento das funções psíquicas superiores. Em síntese, ao evidenciar o psiquismo humano e seu caráter social, a Teoria Histórico-Cultural permite a relação entre a qualidade do desenvolvimento psíquico e o processo de apropriação da cultura. Psicólogos e educadores precisam se apropriar desse entendimento do funcionamento do psiquismo humano, para construírem processos de aprendizagem/ensino que possibilitem o máximo desenvolvimento das funções psíquicas superiores.

\section{Referências}

BOTTOMORE, Tom. Dicionário do Pensamento Marxista. Rio de Janeiro: Jorge Zahar Editor, 2001.

DUARTE, Newton. Vigotski e o "aprender a aprender": crítica às apropriações neoliberais e pós-modernas da teoria vigotskiana. Campinas, SP: Autores Associados, 2006.

KEILER, P. “Teoria Histórico-Cultural” e "Escola Histórico-Cultural”: do Mito (de volta) à Realidade. n.1, p. 54-59, 2012. Disponível em: www.psyanima.ru. Acesso em: 17 abr. 2013. 
LEONTIEV, Alexis. Desenvolvimento do psiquismo. São Paulo: Centauro, 2004.

LURIA, Alexandre Romanovich. Curso de Psicologia Geral. Volume 1 Introdução Evolucionista à Psicologia. Rio de Janeiro: Civilização Brasileira, 1979.

MARX, Karl. O Capital: crítica da economia política. Livro I. 28. ed. Rio de Janeiro: Civilização Brasileira, 2011.

MARTINS, Lígia Márcia. A formação social da personalidade do professor: um enfoque vigotskiano. Campinas, SP: Autores Associados, 2011.

MARTINS, Lígia Márcia. O desenvolvimento do psiquismo e a educação escolar: contribuições à luz da psicologia histórico-cultural e da pedagogia histórico-crítica. Campinas, SP: Autores Associados, 2013.

PRESTES, Zoia. Quando não é quase a mesma coisa: traduções de Lev Semionovitch Vigotski no Brasil. Campinas, SP: Autores Associados, 2012.

TULESKI, Silvana Calvo. Vigotski: a construção de uma psicologia marxista. 2. ed., Maringá: EDUEM, 2008.

TULESKI, Silvana C.; EIDT, Nadia Mara. A periodização do desenvolvimento do psiquismo: atividade dominante e a formação das funções psíquicas superiores. IN: MARTINS, Ligia Márcia; ABRANTES, Angelo Antonio; FACCI, Marilda Gonçalves Dias. Periodização histórico-cultural do desenvolvimento psíquico: do nascimento à velhice. Campinas-SP: Autores Associados, 2016.

VIGOTSKI, Lev S. Manuscritos de 1929. Educação \& Sociedade. n. 71, Campinas, jul. 2000.

VIGOTSKI, Lev S. Teoria e método em psicologia. 3. ed. São Paulo: Martins Fontes, 2004.

VYGOTSKI, L. S. Obras escogidas. Tomo IV. 2. ed. Madrid: Visor, 2006.

VYGOTSKI, L. S. A construção do pensamento e da linguagem. 2. ed. São Paulo: Martins Fontes, 2009.

VYGOTSKI, L. S. Historia del desarrollo de las funciones psíquicas superiores. Obras Escogidas Tomo III. Disponível em: www.taringa.net/perfil/vygotsky. Acesso em: 21 maio 2010.

VYGOTSKI, L. S. Sete aulas de L. S. Vigotski sobre os fundamentos da pedologia. Organização [e tradução] Zoia Prestes, Elizabeth Tunes; tradução Claudia da Costa Guimarães Santana. 1. ed. Rio de Janeiro: E-Papers, 2018.

VYGOTSKI, Lev. S; LURIA, Alexander R. El instrumento y el signo en el desarrollo del niño. Madri: Fundación Infancia Y Aprendizaje, 2007. 